

\title{
Los sistemas de creencias en la política de drogas en Colombia 2000-2015 \\ Un análisis desde el Marco de Coaliciones Promotoras*
}

\author{
Daniel Acevedo Gómez** \\ Andrés Macías Tolosa***
}

\section{Resumen}

El fracasode la lucha contra las drogas ilícitas en Colombia en las últimas décadas, el aumento en los índices de consumo y la relativa tendencia de algunos países a legalizar ciertas sustancias, hacen relevante retomar el análisis de las políticas públicas encaminadas a enfrentar ese fenómeno, desde enfoques no tradicionales. En ese sentido, este artículo aborda esa problemática desde el enfoque del Marco de Coaliciones Promotoras y busca determinar los sistemas de creencias que han incidido en el diseño y desarrollo de la política de drogas en Colombia, desde el 2000, momento en que se inició el Plan Colombia, hasta que se completó su tercera fase en 2015. El estudio hace uso de la revisión documental como principal método de análisis, enfocándose en los discursos de las élites de la política pública de drogas en el país. Palabras clave: política de drogas; sistema de creencias; Marco de Coaliciones Promotoras;regulación; prohibición.

\section{Systems of beliefs in the Drug Policy in Colombia 2000-2015}

\section{An Analysis from the Advocacy Coalition Framework}

\begin{abstract}
The failure of the war on drugs during the last decades in Colombia, the rise in the levels of consumption and the relative tendency of some countries to legalize certain substances, make it relevant to deepen the analysis, on public policies designed to confront such phenomenon, from non-traditional perspectives. In this sense, this article uses the Advocacy Coalition Framework to determine how the systems of beliefs have influenced the design and development of the policy on drugs in Colombia. The period of analysis begins in 2000, when Plan Colombia was first implemented, until 2015, when the third phase of that Plan was completed. This study uses document analysis as its main method of data collection, focusing especially on speeches performed by the relevant actors within the subsystem of the drug policy in Colombia.
\end{abstract}

Keywords: drug policy; systems of beliefs; Advocacy Coalition Framework; regulation; prohibition.

\section{Os Sistemas de Crenças na política de drogas na Colômbia 2000-2015}

\section{Uma análise desde o Modelo de Coalizões de Advocacia}

\section{Resumo}

O fracasso da luta contra as drogas ilegais na Colômbia nas últimas décadas, o aumento dos índices de consumo e a relativa tendência de alguns países a legalizar certas substâncias, tornam relevante retomar a análise das políticas públicas orientadas a lidar com este fenômeno, desde abordagens não tradicionais. Neste aspecto, este artigo aborda essa problemática desdea abordagem do Modelo de Coalizões de Advocacia e busca determinar os sistemas de crenças que têm influído na concepção e desenvolvimento da política de drogas na Colômbia, desde o ano 2000, ano em que começou o Plan Colombia, até que foi concluida sua terceira fase em 2015. O estudo utiliza a revisão documental como principal método de análise, focando-se nos discursos das elites da política pública de drogas no país.

Palavras-chave: política de drogas; sistema de crenças; Modelo de Coalizões de Advocacia; regulamentação; proibição.

\footnotetext{
* Artículo de investigación. Derivado del proyecto "Análisis de la política de drogas en Colombia"; grupo de investigación: OPERA - Observatorio de Políticas, Ejecución y Resultados de la Administración Pública; línea de investigación: Conflicto, paz y seguridad. Investigador principal: Daniel Acevedo Gómez; Coinvestigador: Andrés Macías Tolosa; Fecha de terminación de la investigación: febrero de 2018.

** Politólogo de la Universidad Nacional de Col ombia. Sociólogo de la Universidad de Antioquia. Especialista en Gobierno, Gerencia y Asuntos Públicos y Magíster en Gobierno y Políticas Públicas de la Universidad Externado de Colombia. Adscrito a la Universidad Externado de Colombia, Colombia. Correo electrónico: danielacevedogomez@gmail.com. ORCID: 0000-0002-3223-6814

** Docente-investigador de la Universidad Externado de Colombia, Colombia. Profesional en Gobierno y Relaciones Internacionales de la Universidad Externado de Colombia. Especialista en Gerencia de la Defensa Nacional de la Universidad Militar Nueva Granada. Magister en Peace and Conflict Studies, Tokyo University of Foreign Studies. Doctorado en Peace and Conflict Studies. Correos electrónicos: hector.macias@uexternado.edu.co, andresmaciastolosa@gmail.com.ORCID:0000-0003-0572-4772
}

Cómo citar este artículo: Acevedo, D. y Macías, A. (2019). Los sistemas de creencias en la política de drogas en Colombia 2000-2015. Un análisis des de el Marco de Coaliciones Promotoras. Estudios de Derecho, 76 (167), pp-pp. 11-40 DOI: $10.17533 /$ udea.esde.v76n167a01

Fecha de recepción: 05/04/2018 Fecha de aprobación: 19/06/2018 


\section{Los sistemas de creencias en la política de drogas en Colombia 2000-2015}

\section{Un análisis desde el Marco de Coaliciones Promotoras}

\section{Introducción}

El fenómeno de las drogas ilícitas ha afectado durante varias décadas la economía, la política y la sociedad colombiana; razón que ha demandado una permanente necesidad de elaborar políticas públicas orientadas a enfrentarlo. Éstas se han apoyado, desde un comienzo, en la política internacional de drogas, la cual se estructuró desde la década de 1960 sobre un aparente sistema de creencias prohibicionista y punitivo que careció de evidencias técnicas y científicas en la toma de decisiones. Después de 50 años de guerra contra las drogas, aún no se ha logrado solucionar el problema del narcotráfico en Colombia -un asunto que cobra aún más relevancia, al haber sido uno de los principales temas discutidos en el acuerdo de paz firmado entre el gobierno y las FARC-EP en 2016-. Por el contrario, cada día surgen nuevas sustancias psicoactivas que escapan a todo tipo de controles y ciertas drogas han comenzado a des-estigmatizarse en algunos sectores sociales; esto, fundamentado en el derecho al libre desarrollo de la personalidad y el consumo responsable. Además, dinámicas derivadas, como el microtráfico, han evolucionado rápidamente al interior del país.

Este panorama ha abierto un debate en el sistema político global, permitiendo replantear el prohibicionismo en varios países, entre ellos Colombia, en donde desde el 2010 se hizo visible un cambio en el subsistema de la política de drogas con un nuevo abordaje del problema ${ }^{1}$. En esa discusión, resultan relevantes las recientes estadísticas en torno a lucha contra las drogas en Colombia, ya que

1 Se considera que ese subsistema de la política pudo haber sido promovido por una probable coalición promotora liderada por el Gobierno Nacional, la cual se identificaría con un sistema de creencias regulador basado en el respeto a los derechos humanos y a la salud pública. 
evidencian que el problema de la creciente oferta y demanda de sustancias psicoactivas no ha podido ser controlado en todos los años de vigencia de la guerra contra las drogas; menos aún, cuando ese fenómeno ha tenido una estrecha relación con el conflicto armado (Duncan et al, 2015). Por ejemplo, según el Estudio Nacional de Consumo de Sustancias Psicoactivas 2013 en Colombia, el índice de personas que en algún momento de su vida han hecho uso de drogas -marihuana, cocaína, basuco, éxtasis o heroína- tuvo un aumento de más del 40 por ciento en un período de 5 años, entre 2008 a 2013 (Ministerio de Justicia y del Derecho y Ministerio de Salud, 2013).

El debate se ha agudizado en los últimos años a raíz del considerable incremento de cultivos de arbusto de coca en el país (UNODC, 2016). Una de las posibles causas de dicha situación puede ser resultado de la decisión tomada por el Gobierno Nacional a través de la Resolución 0006 del 2015, que ordenó la suspensión de la aspersión aérea con glifosato. Lo anterior permite prever que aún se está lejos de eliminar tanto el consumo de drogas como la producción de las mismas, especialmente si se mantiene ese modelo prohibicionista que ha alimentado el desarrollo del mercado ilícito más grande del mundo, el cual beneficia mayoritariamente a las organizaciones criminales que han permeado todas las esferas de la sociedad colombiana.

Puede inferirse así que la actual política de drogas tiene gran parte de la responsabilidad sobre el problema que se ha generado a nivel mundial con estas sustancias, lo que hace relevante analizar la política pública de la guerra contra las drogas, desde enfoques no tradicionales, como lo puede ser el Marco de Coaliciones Promotoras - MCP- (Advocacy Coalition Framework según sus siglas en inglés). Ese enfoque analítico es complejo y requiere un desarrollo que excede el alcance de este documento; por esa razón, y como una primera aproximación a dicho análisis, el presente artículo aborda solo uno de los componentes del MCP al pretender responder la siguiente pregunta de investigación: ¿Cuáles son los sistemas de creencias que han influido en el diseño y desarrollo de la política de drogas en Colombia en el periodo 2000-2015?

En ese sentido, el objetivo de este estudio es determinar esos sistemas de creencias que han podido llegar a incidir en la política de drogas en Colombia, desde el 2000, momento en que se inició el Plan Colombia, hasta que se completó su tercera fase en 2015. La hipótesis que se plantea en esta investigación consiste en que el subsistema de la política de drogas en Colombia ha presentado cambios en los últimos años del periodo de estudio, expresados en un mayor posicionamiento de un posible sistema de creencias regulador, entrando en una mayor tensión con el dominante sistema de creencias prohibicionista. Vale la pena destacar que con esta investigación no se busca argumentar que las decisiones de política pública obedecen, necesariamente, a los cambios en los sistemas de creencias; por el contrario, el marco de análisis utilizado busca plantear una explicación 
más que ayudaría a entender cómo los sistemas de creencias pueden tener alguna incidencia en la toma de decisiones.

La investigación es de carácter netamente cualitativo, siguiendo los lineamientos del MCP, y hace uso de la revisión documental como principal método de análisis, el cual incluye publicaciones científicas, informes y reportes institucionales, discursos de funcionarios de alto nivel del Gobierno colombiano y de otras entidades, así como de actores con injerencia en la política de drogas.

\section{Los sistemas de creencias dentro del MCP como herramienta de análisis de políticas públicas}

El MCP es un enfoque teórico y metodológico que permite explicar la forma en que se producen los cambios en las políticas públicas, teniendo como eje de análisis las ideas (Gómez Lee, 2016). Las ideas conforman sistemas de creencias que se expresan a través de coaliciones promotoras, conformadas por diferentes actores provenientes de múltiples sectores. Estos actores tienen por objetivo mantener o modificar las políticas públicas, agrupándose, oficialmente o no, en dichas coaliciones, las cuales son sensibles tanto a procesos de aprendizaje político interno como a cambios externos. Todo esto se da en el marco de aquello que ha sido conceptualizado como el subsistema de la política.

Este enfoque comenzó a ser desarrollado durante la década de los ochenta por el norteamericano Paul A. Sabatier, dentro del paradigma cognitivista o constructivista, en el cual las ideas o los factores cognitivos tienen alta importancia en la formación de políticas públicas, y no solo la racionalidad o los intereses medibles y concretos (Roth, 2015). Se pretende de esta manera superar, en primer lugar, algunas de las limitaciones del Ciclo de las Políticas Públicas de Harold Laswell, ocasionadas por su linealidad y secuencialidad lógica (Ordóñez, 2013); en segundo lugar, las limitaciones que presentan los enfoques desde abajo (bottom - up) y desde arriba (top-down); y, en tercer lugar, la aparente ausencia de una teoría sobre el papel que juega la investigación y la información técnica y científica en el proceso de la política. El MCP busca así abordar estas tres limitaciones e integrarlas en un nuevo enfoque de análisis (Sabatier, Weible y Mc Queen, 2009).

Este enfoque ha sido puesto a prueba a través de diferentes investigaciones en distintos campos temáticos. Sus primeros esbozos se dieron entre 1981 y 1982 en un seminario dictado por Sabatier en la Universidad de Bielefeld, Alemania. Sabatier continuó desarrollando esos esbozos en los años siguientes, con la colaboración de Hank Jenkins-Smith y, recientemente, de Christopher Weible. Estos autores han ido realizando actualizaciones y ajustes al mismo, siendo los más recientes la reformulación del enfoque en 2007, donde se presentaron ajus- 
tes "para facilitar las aplicaciones del mismo por fuera del sistema pluralista de Estados Unidos y poder aplicarlo en los regímenes corporativistas, como los de la Unión Europea, y en los regímenes ejecutivos autoritarios de algunos países en desarrollo" (Gómez Lee, 2012, p. 12).

Las principales categorías de análisis del MCP incluyen el subsistema de la política, el sistema político global, los sistemas de creencias, las coaliciones promotoras con sus actores y los intermediarios de la política. Esta investigación se centra, de manera específica, en el componente de los sistemas de creencias, los cuales pueden considerarse uno de los de partida del MCP. En ese sentido, el MCP tiene como premisa el análisis de los diferentes sistemas de creencias que componen un subsistema de la política. Los sistemas de creencias son entonces "conjuntos de prioridades de valor y asunciones causales, teorías implícitas sobre cómo alcanzar los objetivos, percepciones sobre el estado del mundo (incluyendo la magnitud del problema), percepciones sobre la eficacia de los instrumentos, etcétera" (Martinon, 2007, p. 295).

Es decir, los sistemas de creencias, son las estructuras de pensamiento y opinión de las élites de las políticas públicas. Estas élites están conformadas por aquellos que se han especializado en una o dos áreas y no en una gran variedad de temas, y tienen poder para influenciar el subsistema de la política (Sabatier y Hunter, 1989, p. 253). Dichas élites se componen de funcionarios de alto nivel del gobierno, congresistas enfocados en el subsistema de su interés, individuos que representan asociaciones u organizaciones sectoriales, académicos altamente reconocidos con influencia en el gobierno y líderes de opinión con capacidad movilizadora.

Las políticas públicas responden así a específicos sistemas de creencias de aquellos actores agrupados en coaliciones promotoras que las formulan y logran que sean aplicadas para el abordaje de situaciones específicas de interés colectivo. Estos sistemas se convierten así en plantillas sobre las cuales se miden y analizan los cambios en las políticas públicas, permitiendo superponer las creencias a manera de mapas cognitivos con las respectivas políticas, operando como una herramienta que permite apreciar la influencia de los diferentes actores en un período de tiempo determinado, así como el papel esclarecedor que ha tenido la información sobre el cambio de las políticas públicas (Martinon, 2007).

Ahora, los sistemas de creencias están organizados en tres niveles jerárquicos, a saber: un primer nivel denominado Núcleo Profundo (Deep Core Beliefs), que responde a las creencias normativas y fundamentales, el cual tiene cubrimiento sobre diferentes subsistemas de la política y, por lo tanto, son resistentes al cambio. Se encuentran aquí valores prioritarios como la libertad y la igualdad, los derechos individuales y colectivos, así como identidades culturales, religiosas o étnicas. Se ubica también en este nivel la tradicional dicotomía entre liberalismo 
y conservadurismo, así como entre izquierda y derecha. (Weible y Sabatier, 2006; Sabatier y Weible, 2007; Gómez Lee, 2016). Igualmente se inscriben aquí valores prioritarios elevados a derechos fundamentales como el derecho a la salud, a la vida, a gozar de un ambiente sano, al libre desarrollo de la personalidad, a la intimidad y a la identidad cultural, entre otros.

En el nivel intermedio están las Creencias del Núcleo de la Política (Policy Core Beliefs), entendidas como aquellas del orden empírico relacionadas directamente con el subsistema de la política. Para Martinon (2007) en este nivel se

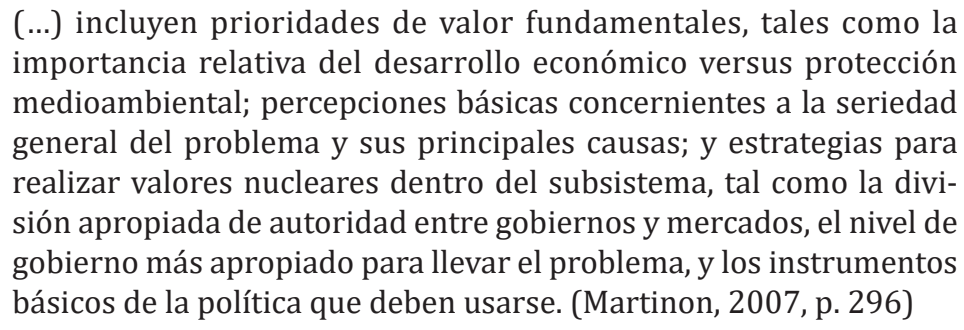

Este nivel presenta una mayor flexibilidad al cambio que el Núcleo Profundo y expresa en sí los elementos que aglutinan las coaliciones promotoras al representar los compromisos e intereses que las élites de la política pública tienen en el subsistema de la política. Allí se han especializado y logrado un nivel de conocimiento sobre lo que consideran es el deber ser y lo que se debe hacer para solucionar determinada problemática que es objeto de la política. Puede entenderse esto como la mirada de largo plazo que tienen las coaliciones promotoras sobre el modelo de individuo deseable y el tipo de sociedad a la que se aspira llegar, más que los intereses particulares y coyunturales.

Finalmente, en el tercer nivel de los sistemas de creencias se encuentran los aspectos o Creencias Secundarias (Secondary Beliefs), que dan cuenta de las creencias específicas en referencia al subsistema de la política y al asunto que lo define, como lo son la composición de la coalición promotora, preferencias por medidas específicas a tomar para el logro de los objetivos o determinadas percepciones sobre asuntos puntuales. Este nivel es el más flexible al cambio a partir de información técnica y científica reciente, así como a sucesos específicos (Sabatier y Weible, 2007). Para el caso de estudio de esta investigación, podrían identificarse como Creencias Secundarias las posiciones frente al gramaje adecuado para la dosis de uso personal, el tipo de sanciones no privativas de la libertad a quienes sean capturados con cantidades superiores a las definidas como dosis para uso personal, la prohibición del consumo en espacio público, las estrategias a desarrollar para la erradicación de cultivos de uso ilícito ante la suspensión de las aspersiones aéreas, entre otras. 
La Tabla 1 presenta una síntesis de estos tres niveles jerárquicos, comparando sus características principales, su alcance y su flexibilidad o posibilidad de cambio. La capacidad del investigador en identificar y diferenciar los tres niveles jerárquicos, le evitarán caer en equívocos al analizar los intercambios y negociaciones de los actores de las coaliciones promotoras, asignando erróneamente relevancia a aquello que no la tiene, y descuidando asuntos que pueden ser determinantes para el cambio en el subsistema de la política.

Tabla 1. Estructura de los sistemas de creencias.

\begin{tabular}{|c|c|c|c|}
\hline & $\begin{array}{c}\text { Núcleo Profundo } \\
\text { (Deep Core Beliefs) }\end{array}$ & $\begin{array}{l}\text { Creencias del Núcleo } \\
\text { de la Política } \\
\text { (Policy Core Beliefs) }\end{array}$ & $\begin{array}{l}\text { Creencias Secundarias } \\
\text { (Secondary Beliefs) }\end{array}$ \\
\hline Características & $\begin{array}{l}\text { Axiomas normativos } \\
\text { y ontológicos. }\end{array}$ & $\begin{array}{l}\text { Posiciones } \\
\text { fundamentales } \\
\text { vinculadas a un } \\
\text { determinado subsistema } \\
\text { de políticas públicas. }\end{array}$ & $\begin{array}{l}\text { Decisiones } \\
\text { instrumentales } \\
\text { necesarias orientadas a } \\
\text { cómo implementar las } \\
\text { políticas públicas. }\end{array}$ \\
\hline Alcance & $\begin{array}{l}\text { Sobre todos los } \\
\text { subsistemas de } \\
\text { políticas públicas. }\end{array}$ & $\begin{array}{l}\text { Específico de un } \\
\text { Subsistema. }\end{array}$ & $\begin{array}{l}\text { Específico de un } \\
\text { Subsistema. }\end{array}$ \\
\hline $\begin{array}{l}\text { Posibilidad de } \\
\text { cambio }\end{array}$ & $\begin{array}{l}\text { Muy baja; } \\
\text { equivalente a } \\
\text { una conversión } \\
\text { religiosa. }\end{array}$ & $\begin{array}{l}\text { Muy difícil. Motivado } \\
\text { por factores externos al } \\
\text { subsistema }\end{array}$ & $\begin{array}{l}\text { Relativamente fácil. En } \\
\text { función de la información } \\
\text { que haya. }\end{array}$ \\
\hline
\end{tabular}

Fuente: Tomado de Estévez y Esper (2008, p. 6).

\section{Evolución de la política de drogas en Colombia y la problematización del narcotráfico}

La denominada guerra contra las drogas se ha librado en todo el globo durante más de 50 años, sin llegar a tener grandes efectos en la reducción de la oferta y el consumo de drogas. Ante este fracaso, la Oficina de las Naciones Unidas contra la Droga y el Delito -ONUDC- ha identificado graves consecuencias negativas no intencionales de esta guerra, la cual por su naturaleza coloca el control del tráfico de drogas en manos del crimen organizado, al mismo tiempo que criminaliza a los consumidores, quienes en la mayoría de los casos no representan problemas para la sociedad, ni son violentos, ni delincuentes. Mientras esto sigue sucediendo, el tráfico ilícito continúa creciendo al tiempo que se destinan vastos recursos para responder represivamente, penalizando a los eslabones más débiles de la cadena. (Lemaitre y Albarracín, 2011; Iturralde y Ariza, 2011; Uprimny, Guzmán y Parra, 2013; Inkster y Comolli, 2013). 
La problematización del narcotráfico en Colombia, es decir su caracterización como un problema público, aunque tiene sus antecedentes a comienzos del siglo, comenzó en la década del 70 del siglo XX, asociándolo con violencia, terrorismo, delincuencia, corrupción y debilidad institucional. Como parte del mismo, el consumo de sustancias psicoactivas -SPA- se ha relacionado con delincuencia juvenil, violencia intrafamiliar, riñas callejeras, violaciones y homicidios, lo que ha derivado en la aparición de diversas interpretaciones y posibles soluciones al mismo problema, materializados en políticas públicas ajustadas a diferentes enfoques (Galán, Pachón y Guerrero, 2008; Room et al, 2013; Toro, 2013; Organización de los Estados Americanos [OEA], 2013a; Comisión Global de Políticas de Drogas [CGPD], 2014).

El camino hacia el prohibicionismo en Colombia se fue consolidando de la mano de la legislación internacional, la cual tuvo como primer antecedente de fiscalización la primera Conferencia Internacional sobre Drogas, conocida como la Comisión del Opio de Shanghai de 1909, a la que le sucedería la Convención Internacional del Opio de 1912. Aunque las drogas hicieron su primera aparición como estupefaciente al ser reportadas internacionalmente en cuanto a los niveles de consumo, importación, exportación, producción, fabricación e inventarios en la Convención Internacional del Opio realizada luego en Ginebra en 1925, su regulación pasó a ser más estricta en 1931 con la Convención de Limitación de la Fabricación y de Regulación de la Distribución de Drogas Narcóticas, la cual exigía a los países firmantes conformar internamente agencias para su control.

Cinco años más tarde, con la Convención para la Supresión del Tráfico Ilícito de Drogas Peligrosas en 1936, dichas agencias nacionales debían asumir tareas de monitoreo e investigación sobre las sustancias fiscalizadas (Inkster y Comolli, 2013). Finalmente, toda la regulación internacional de drogas se consolidaría en tres instrumentos que conforman hoy el triángulo de la política de drogas a nivel global, a saber: la Convención Única de 1961 sobre Estupefacientes, el Convenio sobre Sustancias Psicotrópicas de 1971 y la Convención de Viena de las Naciones Unidas contra el Tráfico Ilícito de Estupefacientes y Sustancias Psicotrópicas de 1988².

Por su lado, Colombia y su estructura normativa en materia de drogas ha estado siempre acorde a los convenios internacionales. Es así que, en la presidencia del conservador antioqueño Belisario Betancur Cuartas se expidió la Ley 30 de 1986, por medio de la cual se adoptó el Estatuto Nacional de Estupefacientes. Éste es hoy en día la base sobre la cual se orienta la política de drogas en Colombia. En esta norma se regula y penaliza el uso, consumo, producción y comercialización

2 Colombia adhiere a la Convención Única de Estupefacientes de 1961 y su Protocolo de Modificaciones de 1972 a través de la Ley 13 del 29 de noviembre de 1974; al Convenio sobre Sustancias Psicotrópicas de 1971 con la Ley 43 del 29 de diciembre de 1980; y en relación a la Convención de Viena contra el Tráfico Ilícito de Estupefacientes y Sustancias Psicotrópicas de 1988 a través de la Ley 67 del 23 de agosto 1993. 
de estupefacientes, pero mientras la Ley definía la cantidad y tipos de sustancia de la dosis para uso personal, al mismo tiempo la penalizaba. El pronunciamiento de la Corte Constitucional a través de la Sentencia C-221 del 5 de mayo de 1994, con ponencia del Magistrado Carlos Gaviria Díaz, fue el punto de partida para poner algunos límites a la política de drogas de corte prohibicionista en Colombia, declarando inexequibles los artículos 51 y 87 de la referida Ley, los cuales definían sanciones para los portadores de la dosis, así como tratamiento y rehabilitación. Al mismo tiempo ratificó la exequibilidad del literal j) del artículo $2^{\circ}$ en el cual se definieron las cantidades de dosis para uso personal, hoy en día vigentes ${ }^{3}$. En dicha Sentencia el Magistrado Gaviria argumentó que se vulneraba el artículo 16 de la Carta Constitucional de 1991, bajo el cual "Todas las personas tienen derecho al libre desarrollo de su personalidad sin más limitaciones que las que imponen los derechos de los demás y el orden jurídico", definiendo así que:

Si el derecho al libre desarrollo de la personalidad tiene algún sentido dentro de nuestro sistema, es preciso concluir que, por las razones anotadas, las normas que hacen del consumo de droga un delito, son claramente inconstitucionales. (Corte Constitucional, Sentencia C-221, 1994)

Precisamente, la tensión en Colombia entre posibles sistemas de creencias que promueven el prohibicionismo y la regulación, ha girado en buena parte durante más de veinte años en torno a esta trascendental jurisprudencia (Larreamendy y Vence, 2011; Camacho, Gaviria, y Rodríguez, 2011; Uprimny, Guzmán, y Parra, 2013).

Los años 90 vieron de esta manera la consolidación de una política de drogas absolutamente prohibicionista, ajustada a un contexto altamente violento, con presencia de múltiples actores armados ilegales, vinculados en la mayoría de los casos al negocio del narcotráfico. Carteles de la droga, grupos guerrilleros y paramilitares confluyeron en una guerra por y contra el Estado, lo que hacía imposible hacer visibles otras formas de abordaje de la problemática. El gobierno de los Estados Unidos abanderaba a nivel mundial la guerra contra las drogas, y Colombia era uno de sus principales aliados en la región.

Al respecto, Renán Vega (2015) hace un recorrido cronológico de la relación que han tenido los Estados Unidos y Colombia desde comienzos del siglo XIX hasta los tiempos actuales. La estructura que define, divide en varias fases los

El artículo 2, literal j) de la Ley 30 de 1986 estableció: “Dosis para uso personal: Es la cantidad de estupefacientes que una persona porta o conserva para su propio consumo. Es dosis para uso personal la cantidad de marihuana que no exceda de veinte (20) gramos; la de marihuana hachís la que no exceda de cinco (5) gramos; de cocaína o cualquier sustancia a base de cocaína la que no exceda de un (1) gramo, y de metacualona la que no exceda de dos (2) gramos. No es dosis para uso personal, el estupefaciente que la persona lleve consigo, cuando tenga como fin su distribución o venta, cualquiera que sea su cantidad." 
momentos de esa relación. Es de particular interés la fase IV titulada De la Contrainsurgencia Moderna al Plan Colombia (1962-1999), en la cual denomina como Narcotización Contrainsurgente la estrategia intervencionista norteamericana de lucha contra las drogas, donde la certificación que exigieron los Estados Unidos desde 1986 -año en que se expide el Estatuto Nacional de Estupefacientes- a los países productores de drogas, operó como "un instrumento de índole colonial, porque un poder externo decide a su arbitrio a qué país se le proporciona ayuda económica, asistencia técnica y cuenta con el beneplácito de los Estados Unidos" (2015, p. 34). Para comienzos de los años 90, específicamente en el Gobierno de César Gaviria (1990-1994), afirma que:

Colombia participa en la lucha contra la economía transnacional de narcóticos en los términos planteados por Washington, con lo cual accede a créditos y se convierte en el principal receptor de asistencia militar en la región, lo que cimenta su posición dependiente y subordinada. El tema antinarcóticos se torna en un mecanismo clave de intervención e injerencia en Colombia. (...) La lucha anti-narcóticos se utiliza de manera oportunista por consideraciones de orden político, puesto que Estados Unidos tolera y fomenta redes de narcotraficantes, si éstas son funcionales a sus intereses y además garantiza la existencia de la economía transnacional de narcóticos. (Vega, 2015, p. 35)

Después de César Gaviria, el gobierno de Ernesto Samper (1994-1998) se caracterizó por los escándalos sobre apoyo de dineros del narcotráfico a su campaña presidencial. Esa situación dejó serias secuelas a nivel interno y generó una enorme tensión con el gobierno de Estados Unidos, llevando la política a un periodo de relativo estancamiento. Una vez finalizado el gobierno de Samper, la política colombiana de guerra contra las drogas retomó el curso y se alineó nuevamente al eje norteamericano. En un contexto prohibicionista y con el recrudecimiento del conflicto armado en Colombia, el cual se alimentaba de las rentas que el narcotráfico le generaba tanto a guerrillas como a paramilitares, los gobiernos siguientes asumieron posturas acordes a la normatividad internacional, reafirmada por la declaración política de la Sesión Especial de la Asamblea General de las Naciones Unidas que abordó el problema mundial de las drogas en 1998.

Luego vino el Plan Colombia con el objetivo de luchar contra el narcotráfico, fortalecer la institucionalidad, recuperar la seguridad y consolidar el desarrollo social en el país. Comienza así un nuevo siglo con la misma política prohibicionista, la cual se agudizó con la lucha internacional contra el terrorismo en respuesta a los ataques del 11 de septiembre de 2001 en los Estados Unidos, anulando temporalmente la posibilidad de buscar nuevas estrategias frente al problema de las drogas, las cuales empezarían a emerger lentamente a finales de la primera década del Siglo XXI, llevando a cambios en el subsistema de la política de drogas. 


\section{Sistemas de creencias en la política de drogas en Colombia}

Para hacer un acercamiento a los posibles sistemas de creencias que se presentan en el subsistema de la política de drogas en Colombia, se considera necesario, en primer lugar, delimitar tres conceptos fundamentales que en el debate público hacen presencia, como lo son: prohibición, regulación y legalización. Estos conceptos se detallan en la Tabla 2, donde además se incluye la visión que tanto la Comisión Global de Políticas de Drogas -CGPD-, como la Organización de los Estados Americanos. -OEA- plantean sobre cada uno de ellos. De esa forma, se busca evitar equívocos en el proceso investigativo, asumiendo sistemas de creencias que en otros países pueden tener fuerte presencia en el subsistema y pueden contar con una coalición promotora que lo asuma, pero que no corresponden a la realidad colombiana.

Estas claridades conceptuales permiten suponer para Colombia la existencia de dos sistemas de creencias, el prohibicionista y el regulador, los cuales tienen su expresión a nivel mundial en los diferentes escenarios de toma de decisiones sobre la política de drogas.

Aunque en la Tabla 2 se presentan las definiciones de prohibicionismo, regulación y legalización, es posible afirmar que para el caso colombiano, la tendencia a la legalización es mínima, por lo que se puede inscribir dentro del mismo sistema de creencias regulador. En el debate sobre cuál debe ser el proceder del Estado en la materia, solo se presentan dos posturas: prohibir o regular. Esto no elimina la posibilidad de contar a futuro con un sistema de creencias legalizador, como lo hay en países como Estados Unidos y Uruguay, pero en Colombia aún no hay un contexto favorable ni élites de las políticas públicas que integren una coalición promotora madura que permita el desarrollo de este sistema de creencias.

Al interior de ambas posturas, al parecer se demarcan tendencias que podrían definirse también como más radicales y otras más flexibles o con sus respectivos matices. Ambas van tomando protagonismo e incidencia en las decisiones de política según la solidez y organización de las que serían las coaliciones promotoras, la madurez del subsistema de la política y las tensiones en el sistema político global. A continuación, se hace una caracterización de aspectos que sirven de indicios de los posibles sistemas de creencias, definiendo sus postulados centrales, operacionalizando los componentes de los tres niveles jerárquicos y dando cuenta cómo se expresan a partir de los discursos de las élites de las políticas públicas que los representan. 


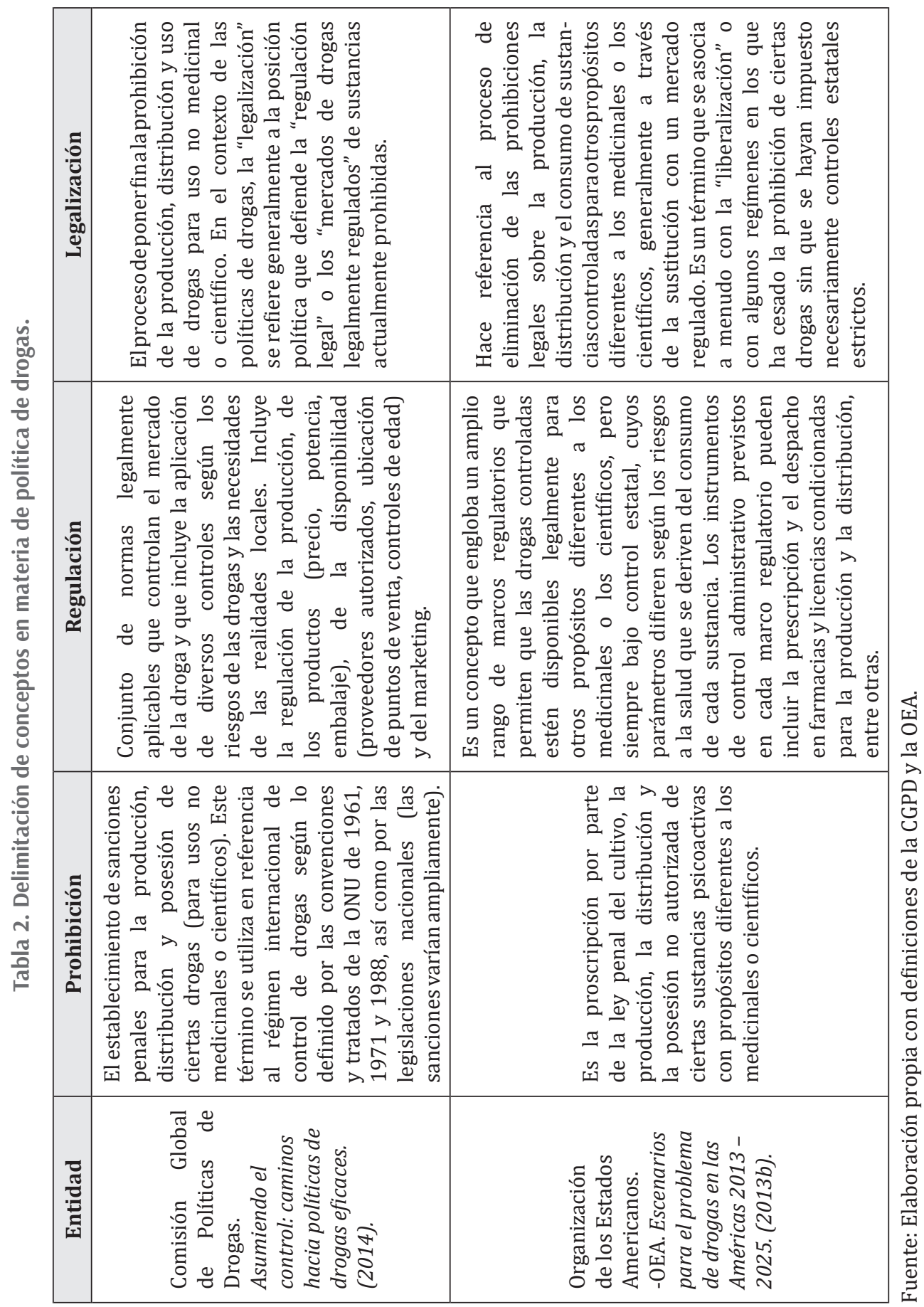




\subsection{Sistema de creencias prohibicionista}

El sistema de creencias prohibicionista es aquel que considera que debe prohibirse y/o penalizarse el cultivo, producción, distribución, posesión y/o consumo de sustancias psicoactivas que se encuentran fiscalizadas a nivel internacional. En Colombia, este sistema de creencias se vino a consolidar recién en las últimas tres décadas. La manera en que el prohibicionismo se ha instaurado como el sistema de creencias que define el subsistema de la política de drogas se puede evidenciar a través de una investigación realizada por Uprimny, Guzmán y Parra (2013), quienes establecen cinco etapas en la evolución de la legislación penal sobre drogas en el país.

En la etapa 1 se pasa de una regulación preventiva a las primeras represiones, periodo comprendido entre los años 20's y los 60's; la etapa 2 está determinada por la influencia creciente de los tratados internacionales y la búsqueda de articulación de las represiones en los años 70's; en la etapa 3 comienza la búsqueda de la integralidad de la regulación a través del Estatuto Nacional de Estupefacientes o Ley 30 de 1986, en los años 80's; la etapa 4 se enmarca en la aprobación con reservas de la Convención de Viena de 1988; y la etapa 5, es definida por los autores como aquella que se debate entre la despenalización judicial del consumo y su prohibición constitucional, la cual comienza con la Sentencia C-221 de 1994 sobre dosis mínima personal hasta el Acto Legislativo 02 de 2009 y la incertidumbre jurídica generada por el mismo, que fue superada por sentencias tanto de la Corte Suprema de Justicia como de la Corte Constitucional en los años siguientes.

Como se indicó, es a partir de la etapa 3 que empieza a operar integralmente en Colombia el prohibicionismo, en tanto la Ley 30 de 1986 se encuentra vigente y ha sido en torno a ella que se han dado los debates más álgidos en materia de drogas. Tal fue el caso de la Sentencia C-221 de 1994, que, como se indicó anteriormente, declaró inexequibles los artículos 51 y 87 de dicha norma, los cuales definían sanciones para los portadores de la dosis mínima, así como tratamiento y rehabilitación. De esta manera, pareciera que el prohibicionismo no es un sistema de creencias fijo o estático, sino que es dinámico dentro de sus límites, ya que en su interior pueden presentarse tensiones por parte de coaliciones promotoras que pretendan hacerlo más estricto o flexible.

La operacionalización de los componentes de lo que podría llegar a ser cada sistema de creencias, que se muestra en la Tabla 3 -y en la Tabla 5 para el sistema de creencias regulador-, es un requisito para una adecuada aplicación del MCP. Esto permite acercarse a su posible estructura, identificando aquellas creencias del núcleo profundo, las creencias del núcleo de la política, así como las creencias secundarias. 


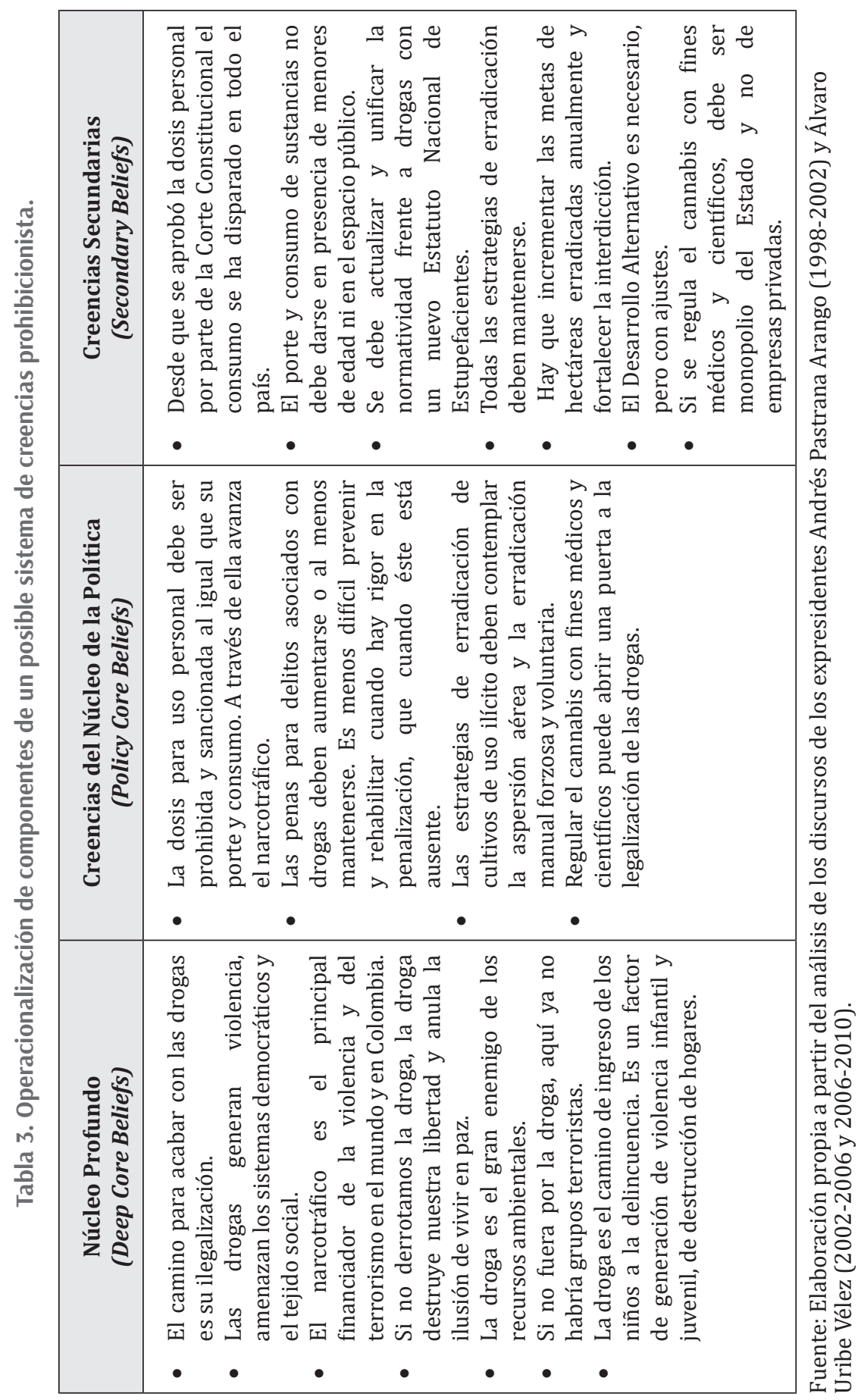


Finalmente, la forma en que los componentes arriba presentados se expresan, es a partir de los discursos e intervenciones de las élites de las políticas públicas que los representan, quienes, por su nivel de credibilidad, poder y liderazgo, los refuerzan en diferentes escenarios internacionales como nacionales, buscando aglutinar actores a su alrededor, recibir respaldo financiero y político, al igual que mantener la convicción de la ciudadanía sobre este tipo de políticas.

Para analizar esas formas de expresión, se seleccionaron fragmentos de discursos de los expresidentes Andrés Pastrana Arango (1998-2002) y Álvaro Uribe Vélez (2002-2006 y 2006-2010), así como del Ministro del Interior y de Justicia, Carlos Holguín Sardi (22 de agosto de 2006 - 20 de junio de 2008), y del Ministro de la Protección Social, Diego Palacio Betancourt (10 de febrero de 2003 - 7 de agosto de 2010). Para una mayor comprensión de la forma en que se expresa este sistema de pensamiento, se identificaron los temas con los que recurrentemente se asoció la problemática a fin de fortalecer el mismo, en tanto la opinión pública estaría más proclive a respaldar las políticas que propendieran por el prohibicionismo. Estos temas fueron la protección de la niñez y la juventud, el medio ambiente y los recursos naturales, la institucionalidad y la democracia, y la violencia y el terrorismo. Ese análisis se resume en la Tabla 4.

Llama la atención en los discursos presentados, cómo las élites acudieron a referenciar la problemática, acusando la droga como fuente de amenaza, y no englobándola en el problema del narcotráfico, acudiendo además a figuras como microtráfico asesino, negocio criminal, peligro de contagio, gran destructor de la ecología, cadena de muerte y de dolor, amenaza y desestabilizar esta América Latina, entre otras, lo que permite generar mayor identidad y respaldo a su discurso en el grueso de la población.

Para el período de análisis se identificó además que entre los años 2000 y 2010, durante la presidencia de Andrés Pastrana Arango y los dos períodos de Álvaro Uribe Vélez, fue cuando más énfasis se hizo en el modelo prohibicionista, motivo por el cual los fragmentos seleccionados corresponden a ese período de tiempo, situación que cambia en el período de gobierno de Juan Manuel Santos Calderón, como se verá más adelante. Si se tiene en cuenta que el MCP resalta el papel de las élites de las políticas públicas en su incidencia en el subsistema de la política, se da relevancia a las intervenciones de los presidentes y los ministros, quienes ante la hegemonía del prohibicionismo, al cual representaban, se ubicaban en un lugar de enunciación determinante para incidir en el subsistema. 
Daniel Acevedo Gómez y Andrés Macías Tolosa

\begin{tabular}{|c|c|c|c|c|}
\hline \multirow{3}{*}{ 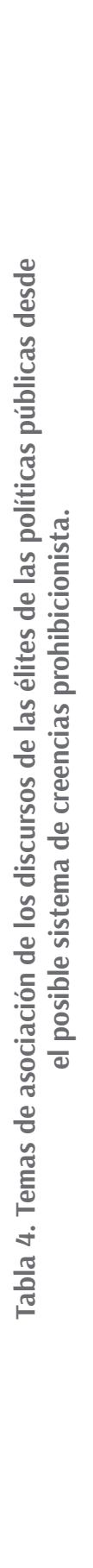 } & 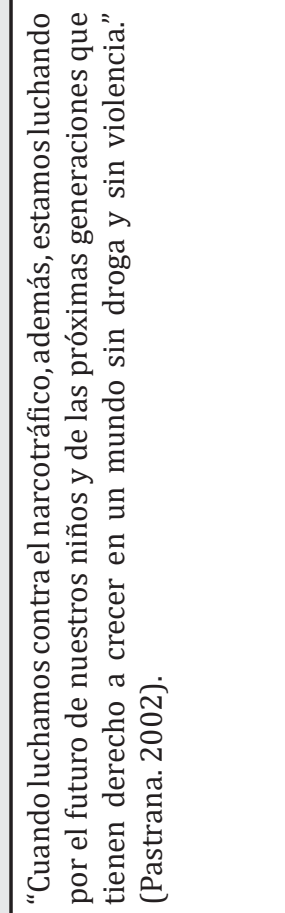 & 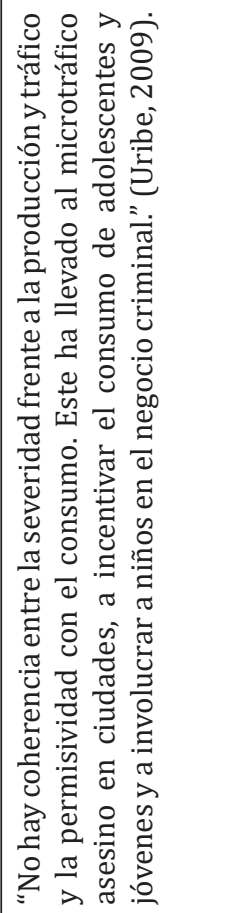 & 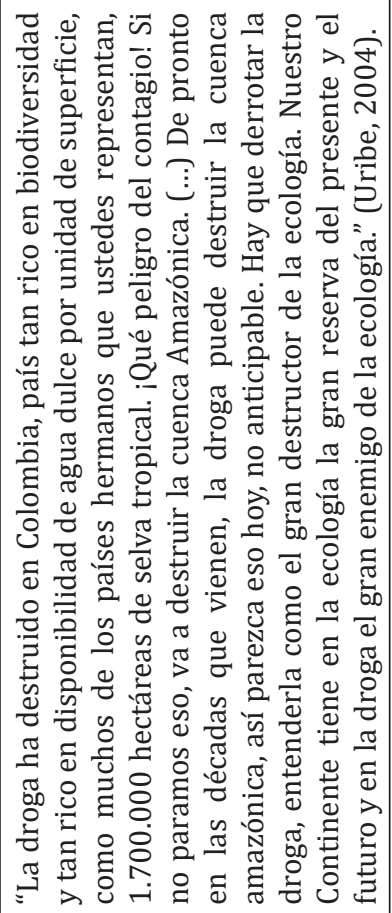 & 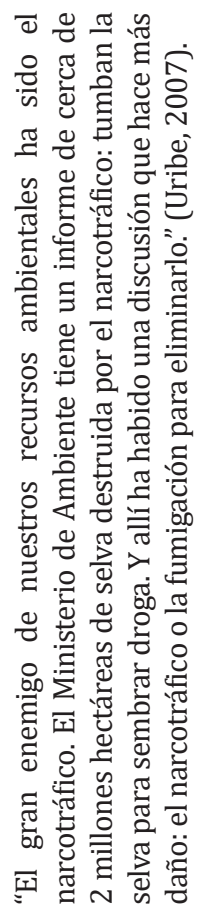 \\
\hline & 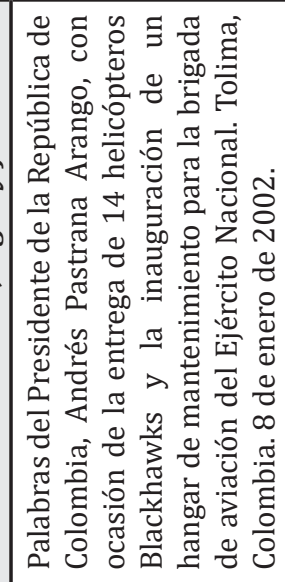 & 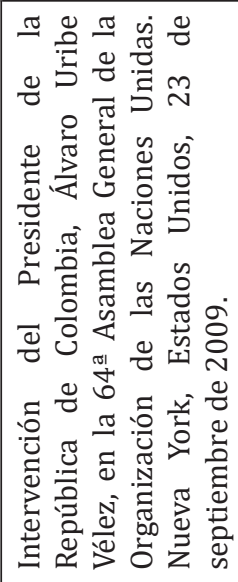 & 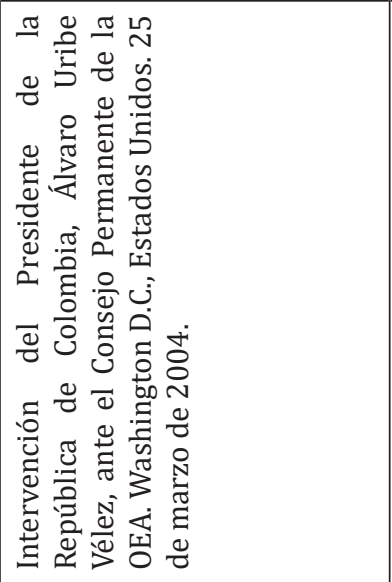 & 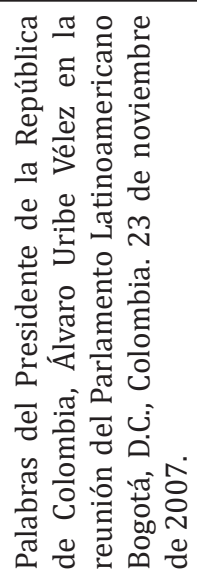 \\
\hline & 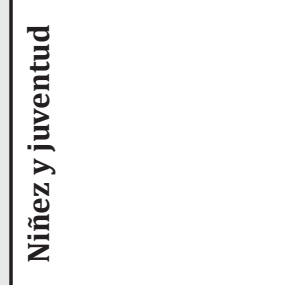 & &  & \\
\hline
\end{tabular}




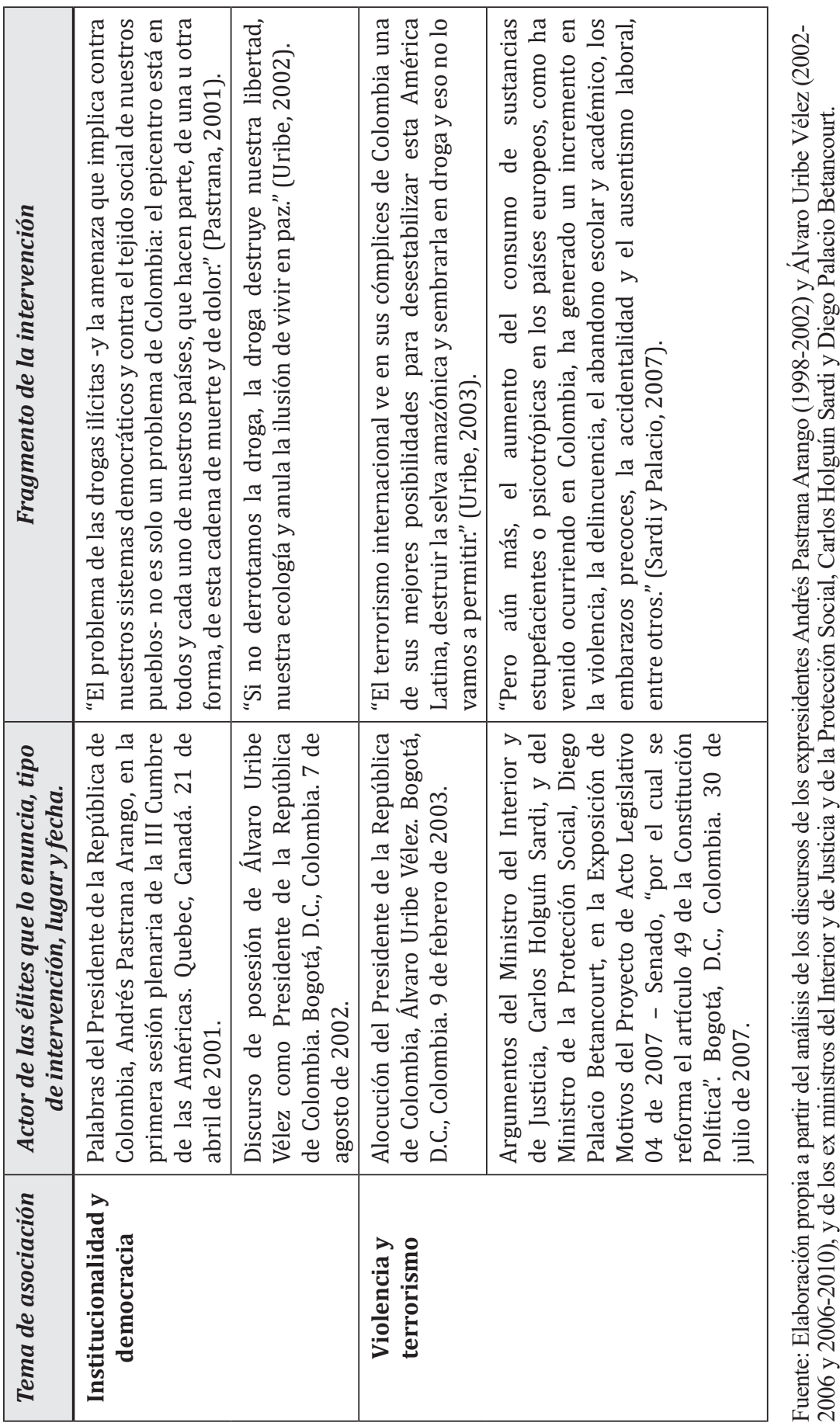




\subsection{Sistema de creencias regulador}

Es el sistema de creencias que considera necesario definir marcos regulatorios que permitan que las drogas estén disponibles legalmente para propósitos como los medicinales o los científicos, así como los de uso recreativo, ya sea bajo control estatal o con la participación del sector privado, cuyos parámetros pueden diferir según los riesgos a la salud que se deriven del consumo de cada sustancia. Argumenta este sistema que el Estado debe entrar a controlar y regular todo lo relacionado con el cultivo, la producción, la distribución, la posesión y el consumo de sustancias psicoactivas en tanto actualmente lo hace la criminalidad, generando problemas asociados a la violencia, la salud pública, la afectación del medio ambiente, corrupción, debilidad institucional, entre otros. La Comisión Global de Política de Drogas, integrada entre otros por el expresidente de Colombia, César Gaviria Trujillo, y exfuncionarios de organismos internacionales, manifestó en su informe del año 2014 que:

(...) a largo plazo, los mercados de drogas deberán estar regulados
de manera responsable por las autoridades de gobierno. Sin la
regulación, control y aplicación de las leyes, el tráfico de drogas
permanecerá en manos de criminales organizados. En última
instancia se trata de elegir entre dar el control al gobierno o a los
carteles; no hay una tercera opción en que se pueda hacer desa-
parecer los mercados de drogas. (Comisión Global de Política de
Drogas, 2014, p. 28)

Recientemente, la marihuana, como sustancia controlada dentro de las convenciones internacionales, ha empezado a ser regulada de una manera experimental en la que décadas atrás no habría sido posible. La información técnica y científica ha permitido realizar cambios en las políticas públicas de varios países del hemisferio como en los Estados Unidos, donde diferentes Estados han venido modificando sus normas, manteniendo marcos legales dentro del prohibicionismo penalizador, así como despenalizador, hasta marcos regulatorios y de legalización a través de la participación del sector privado en la producción y comercialización de la sustancia con fines medicinales y recreativos. (Galston y Dionne, 2013; Bewley-Taylor, Blickman, y Jelsma, 2014; y Csete, 2014).

El cambio en la coalición de gobierno en Colombia en el año 2010 abrió la puerta a nuevas discusiones al interior del subsistema, intensificándose tanto el debate como la producción académica en torno al tema. Es a partir de este año que comienza a plantearse la necesidad de revaluar el modelo prohibicionista buscando alternativas que se centren en la salud pública y los derechos humanos y no en la criminalización. Irrumpe de esta manera un pensamiento 
regulador, el cual había contado desde décadas atrás con defensores, pero no con una agrupación promotora en la que actores como el Presidente de la República, Juan Manuel Santos Calderón, ministros y congresistas, así como investigadores de reconocidas universidades y centros de pensamiento, se articularan de una manera más organizada para intentar modificar el subsistema de la política de drogas.

Dentro de dicha agrupación se presentan matices tendientes a dar prelación al control estatal en lo referente a las drogas, como aquellos donde se promueve la participación del sector privado tanto en el cultivo, producción y distribución de las mismas, asociándose de esta manera con la liberalización de los mercados. Así ocurre actualmente en Colombia con sustancias como el tabaco y el alcohol, las cuales se encuentran reguladas pero su oferta recae en manos tanto del sector público como del privado.

En el ejercicio de operacionalización de los componentes del posible sistema de creencias regulador, se identificaron también aquellos que corresponden a las creencias del núcleo profundo, las creencias del núcleo de la política, así como las creencias secundarias. Ese análisis se presenta en la Tabla 5.

En línea con la información y el análisis llevado a cabo anteriormente, en la Tabla 6 se presentan fragmentos de discursos e intervenciones de las élites de las políticas públicas que representan aquello que podría llegar a ser un sistema de creencias regulador, centrando la atención en las del presidente Juan Manuel Santos, así como del Ministro de Justicia y del Derecho, Yesid Reyes.

Santos, quien llegó al poder en el año 2010, marcó una ruptura con sus antecesores frente a la política de drogas, con posiciones basadas en el respeto a los derechos humanos y la salud pública, siendo el primer presidente que, no solo en el período de estudio, sino desde que la droga y el narcotráfico fueron problematizados en Colombia en los años 70, asume una posición de liderazgo internacional de crítica frente a los enfoques tradicionales basados en el prohibicionismo, impulsando la revisión y el cambio de estrategias, acorde a la nueva evidencia científica, la cual ha dado cuenta del fracaso de la denominada guerra contra las drogas.

Se identificaron también los temas con los que recurrentemente se asoció la problemática, tales como la necesidad de revisar la estrategia mundial contra las drogas ilícitas con base en información científica, el fracaso de la guerra contra las drogas, asumir un enfoque de derechos humanos y salud pública, proteger el medio ambiente y los recursos naturales, combatir los eslabones fuertes de la cadena del narcotráfico y tener alternativas para los eslabones débiles, conformación de un bloque regional que impulse la revisión de la política de drogas ante la ONU $\mathrm{y}$, finalmente, el riesgo que genera el narcotráfico como generador de violencia y terrorismo. 


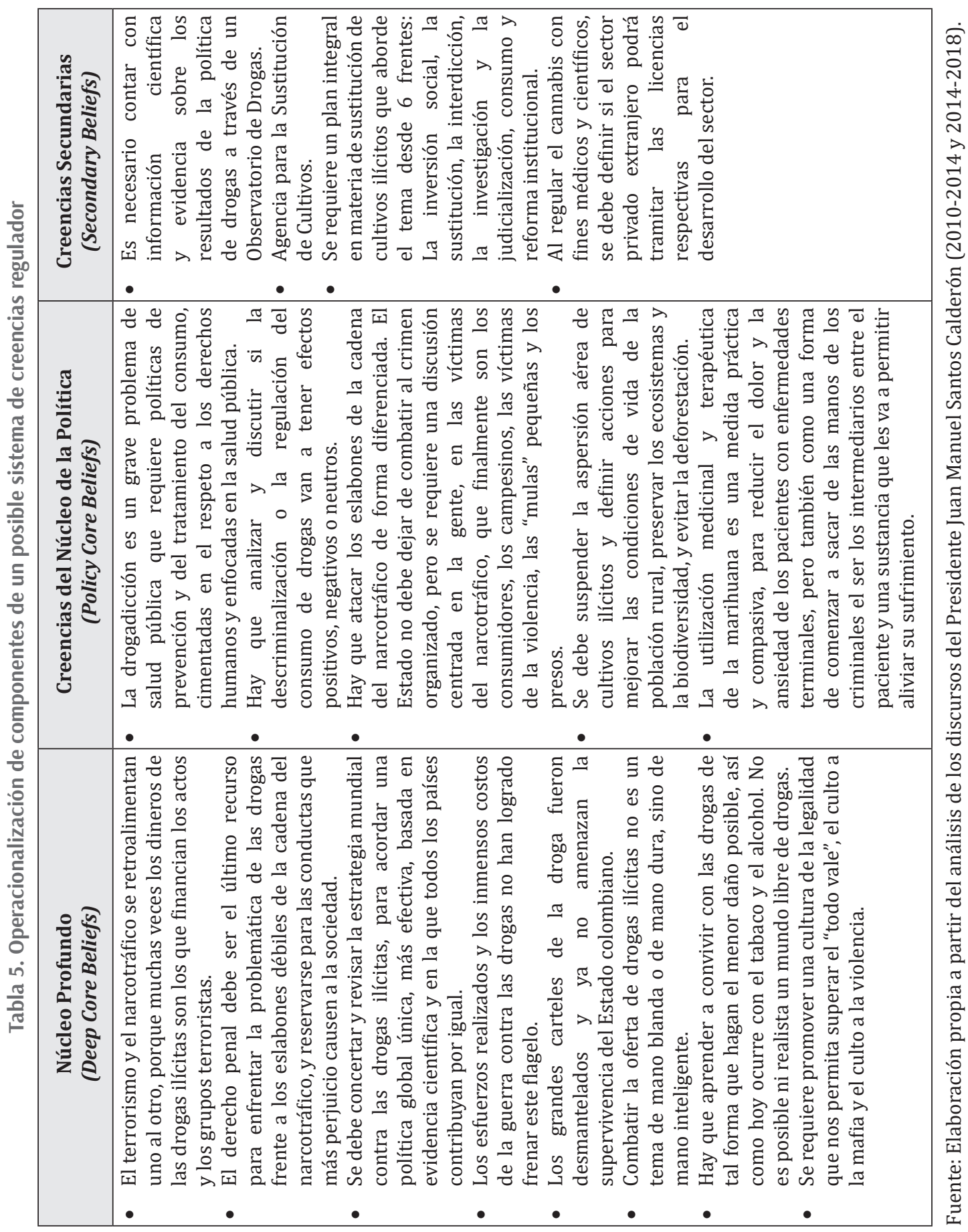


A diferencia de los contenidos enunciados por las élites de las políticas públicas en la primera década del siglo XXI, tiempo en el cual fue hegemónico el prohibicionismo, entre los años 2010 y 2015 los discursos y las prácticas se orientaron hacia la promoción de políticas basadas en los derechos humanos y la salud pública. Eventos externos al subsistema de la política de drogas como el cambio en la coalición de gobierno y el inicio de los diálogos para lograr un acuerdo de paz entre el Gobierno y la guerrilla de las FARC-EP, sumado a cambios de opinión a nivel mundial, también incidieron directamente en este.

A nivel interno del subsistema, se identifican los cambios en materia de política de drogas frente a sustancias como la marihuana en diferentes Estados de los Estados Unidos, así como en Uruguay (Uprimny, 2013; Bermúdez, 2013). A eso, se suman los giros dados a nivel interno sobre dosis personal y de aprovisionamiento, las aspersiones aéreas con herbicida glifosato y la reglamentación de la marihuana con fines médicos y científicos. Además, se abrió campo a una posición política basada en el diálogo y el consenso, impulsada por el Gobierno Nacional, que empezó a generar cuestionamientos sobre el modelo prohibicionista, presentándose nueva información y evidencia científica. 


\begin{tabular}{|c|c|c|c|c|}
\hline 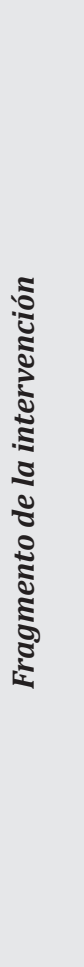 & 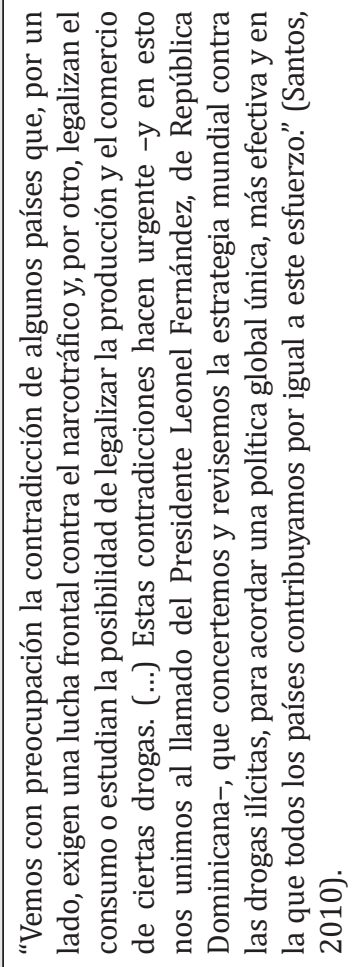 & 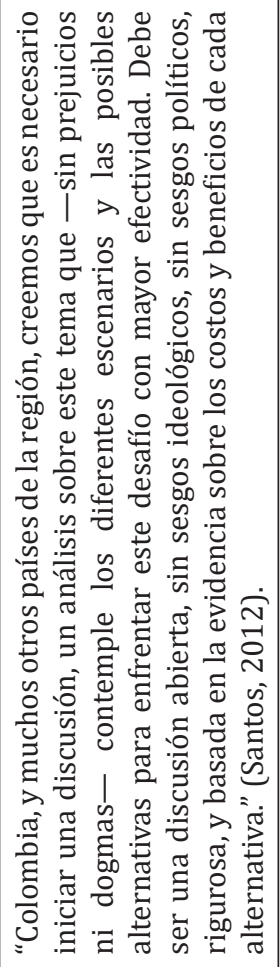 & 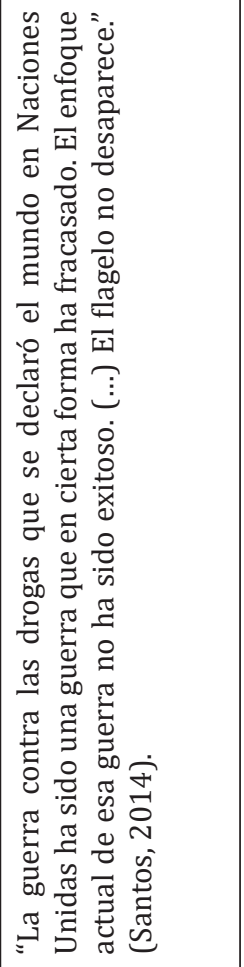 & 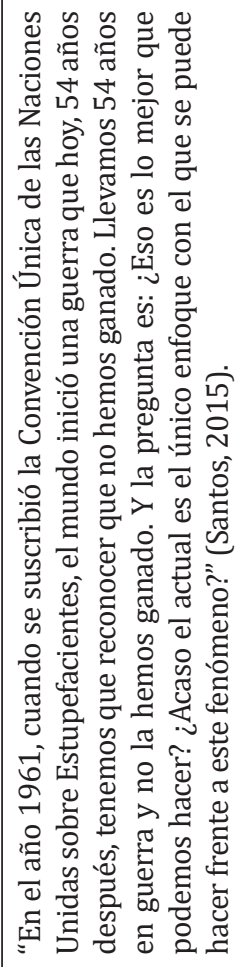 \\
\hline 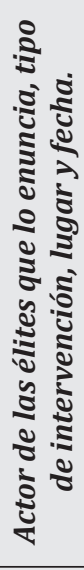 & 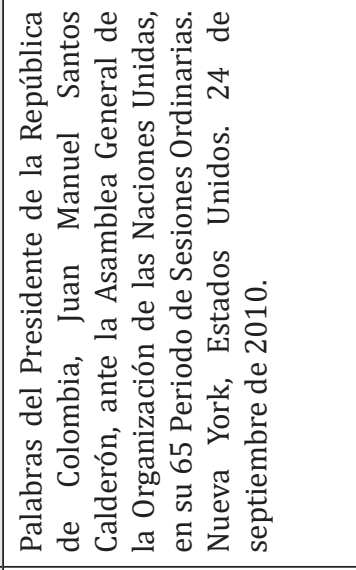 & 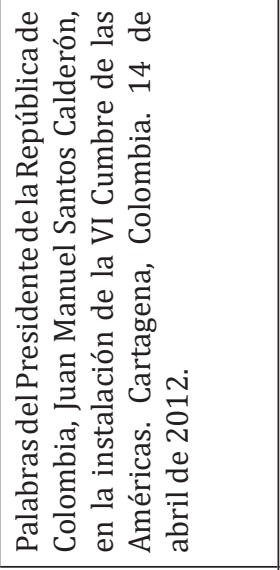 & 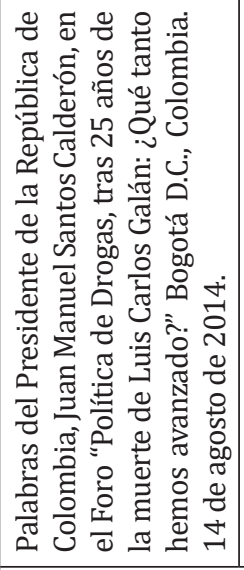 & 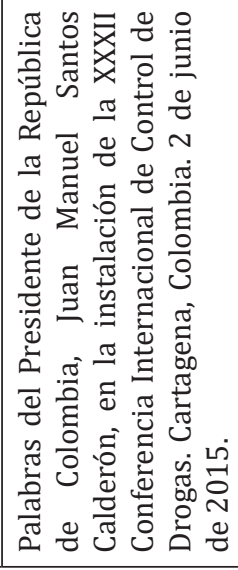 \\
\hline 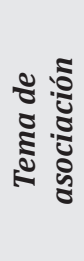 & 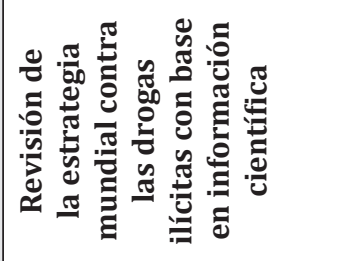 & & 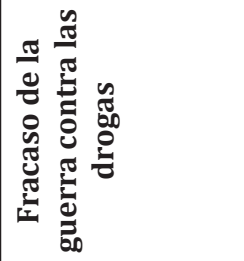 & \\
\hline
\end{tabular}




\begin{tabular}{|c|c|c|}
\hline 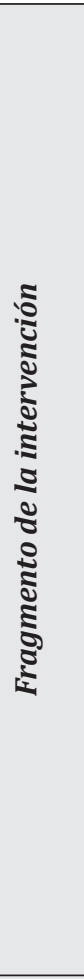 &  &  \\
\hline 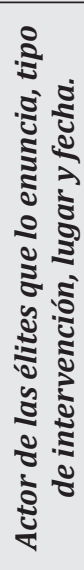 & 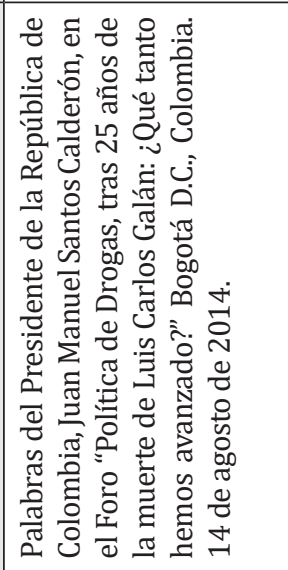 & 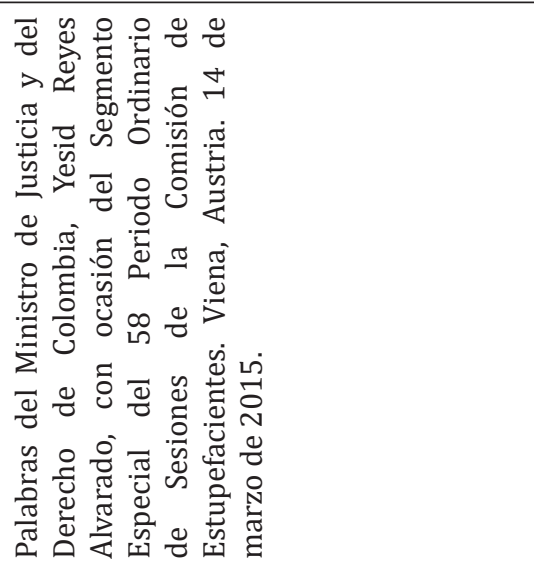 \\
\hline 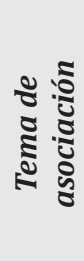 &  & \\
\hline
\end{tabular}




\begin{tabular}{|c|c|c|c|}
\hline  &  &  & 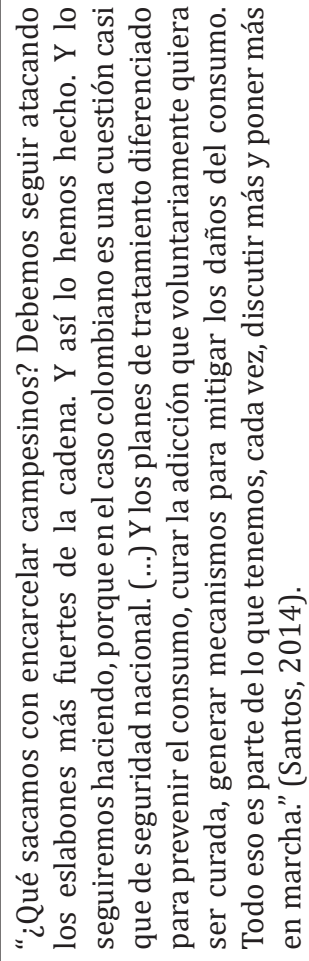 \\
\hline 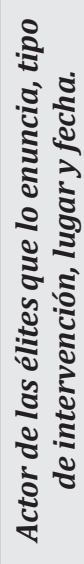 & 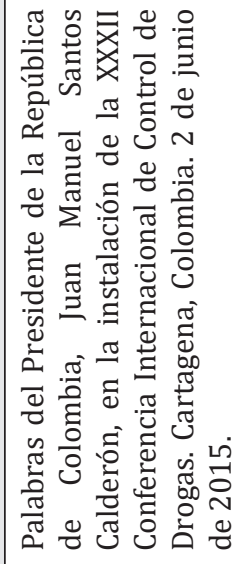 & 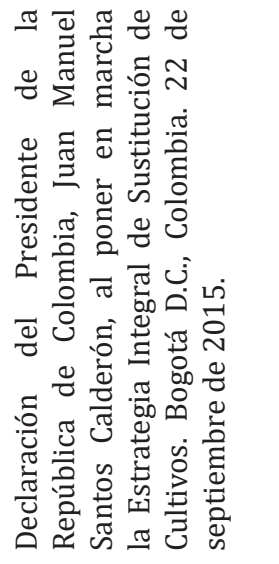 & 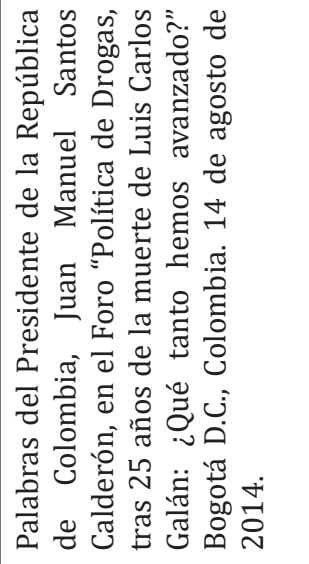 \\
\hline 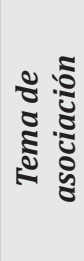 & 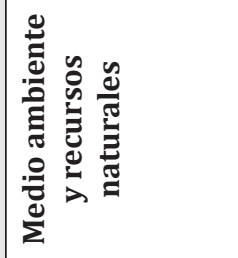 & & 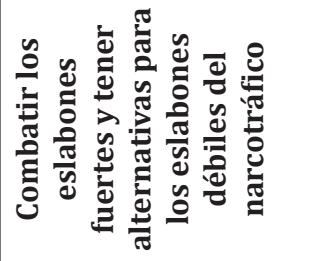 \\
\hline
\end{tabular}









\section{Conclusiones}

Con base en los lineamientos del MCP, en el subsistema de la política de drogas en Colombia se pueden identificar dos claros sistemas de creencias: el prohibicionista y el regulador. Si bien se puede hablar, de manera conceptual, de un tercer sistema de creencias -el legalizador-, no es posible aún identificar una coalición promotora que lo promueva.

De esos sistemas de creencias, se encontró que el prohibicionista fue el primero que se consolidó en el país, especialmente a través del Estatuto Nacional de Estupefacientes de 1986. Al interior de ese sistema de creencias, se evidenciaron tensiones y debates constantes, pero la posibilidad de un cambio en él era muy baja, ya que las élites que dominaban ese sistema de creencias lograban generar una gran identidad y un fuerte respaldo alrededor de la idea de la droga como una amenaza a la población y, por ende, la necesidad de su prohibición. Esa connotación de amenaza se mantuvo vigente en el núcleo profundo del sistema de creencias por décadas.

Sin embargo, en 2010 cambió la coalición de gobierno, situación que abrió la posibilidad de entablar nuevas discusiones al interior del subsistema de la política de drogas. La llegada del presidente Santos marcó una ruptura con los gobiernos anteriores, ya que llegó con unas ideas que reemplazaban ese concepto de amenaza a la población, por la relevancia del respeto a los derechos humanos y a la salud pública. Así se fue fortaleciendo el sistema de creencias regulador, apoyado adicionalmente por los resultados negativos del modelo prohibicionista y por eventos externos al subsistema de la política, como el apoyo internacional a enfoques no tradicionales y los diálogos de paz con las FARC-EP. Es importante destacar que en todo este proceso, las decisiones de la Corte Constitucional jugaron un rol relevante en la consolidación de uno u otro sistema de creencias.

Así se puso en duda la política de drogas basada en el prohibicionismo, generando a su vez un cambio de actitudes en las élites de las políticas.

\section{Referencias}

Bermúdez, A. (4 de septiembre de 2013). Estados Unidos, otro paso más cerca de enterrar política antidrogas. Recuperado de: http://lasillavacia.com/historia/ estados-unidos-otro-paso-mas-cerca-de-enterrar-politica-antidrogas-45557

Bewley-Taylor, D., Blickman, T., y Jelsma, M. (2014). Auge y caída de la prohibición del cannabis. La historia del cannabis en el sistema de control de drogas de la ONU y opciones de reforma. Amsterdam: Transnational Institute.

Camacho, A., Gaviria, A., y Rodríguez, C. (2011). El consumo de droga en Colombia. En Alejandro Gaviria Uribe y Daniel Mejía Londoño (Eds.), Políticas antidroga en Colombia: éxitos, fracasos y extravíos (pp. 41-65). Bogotá: Ediciones Uniandes.

Comisión Global de Políticas de Drogas. (2011). Guerra a las drogas. Recuperado de: www.globalcommissionondrugs.org 
Comisión Global de Políticas de Drogas. (2014). Asumiendo el control: caminos hacia políticas de drogas eficaces. Recuperado de: http://www.gcdpsummary2014.com

Corte Constitucional de Colombia. Sentencia C-221 (1994). [MP Carlos Gaviria Díaz]

Csete, J. (2014). Cost and benefits of drug-related health services. En Ending the Drug Wars. Report of the LSE Expert Group on the Economics of Drug Policy (pp. 70-76). United Kingdom: LSE.

Duncan, G. et al. (2005). Narcotráfico en Colombia. Economía y violencia. Bogotá: Fundación Seguridad y Democracia.

Estévez, A., y Esper, S. (2008). Las políticas públicas cognitivas: El enfoque de las coaliciones defensoras. Buenos Aires: Centro de Investigaciones en Administración Pública. Facultad de Ciencias Económicas de la Universidad de Buenos Aires.

Galston, W., y Dionne, E. J. (2013). The New Politics of Marijuana Legalization: Why Opinion is Changing (p. 17). Washington D.C.: Brookings Institution. Recuperado de: http://www.brookings.edu/research/papers/2013/05/29-politics-marijuanalegalization-galston-dionne

Gómez L., M. I. (2012). El Marco de las Coaliciones de Causa -Advocacy Coalition Framework-. Revista OPERA No. 12. Bogotá: Universidad Externado de Colombia.

Gómez L., M. I. (2016). Biodiversidad y políticas públicas. Coaliciones de causa en las políticas de acceso a recursos genéticos en Colombia. Bogotá: Universidad Externado de Colombia.

Inkster, N., y Comolli, V. (2013). Drogas, inseguridad y Estados fallidos. Bogotá: Ediciones Uniandes.

Iturralde, M., y Ariza, L. J. (2011). El tratamiento penal del narcotráfico y delitos conexos. En A. Gaviria Uribe y D. Mejía Londoño (Eds.), Políticas antidroga en Colombia: éxitos, fracasos y extravíos (pp. 271-300). Bogotá: Ediciones Uniandes.

Larreamendy - Joerns, J., y Vence, M. F. (2011). La demanda como drama: la prevención y el tratamiento del uso de drogas en Colombia. En A. Gaviria y D. Mejía (Eds.), Políticas antidroga en Colombia: éxitos, fracasos y extravíos (pp. 121-145). Bogotá: Ediciones Uniandes.

Martinon Q. R. (2007). La incorporación de las ideas al análisis de políticas públicas en el marco de las coaliciones promotoras. Gestión y Política Pública. Vol. XVI. Núm. 2, pp. 281-318.

Ministerio de Justicia y del Derecho y Ministerio de Salud. (2013). Estudio Nacional de Consumo de Sustancias Psicoactivas en Colombia 2013. Colombia.

Organización de los Estados Americanos. (2013). El problema de las drogas en Las Américas. Recuperado de: http://cicad.oas.org/Main/Template.asp?File=/drogas/elinforme/default_spa.asp

Ordóñez-Matamoros, G. (2013). Manual de análisis y diseño de políticas públicas. Bogotá: Universidad Externado de Colombia.

Roth D. A. (2015). Políticas públicas. Formulación, implementación y evaluación. Bogotá: Aurora.

Reyes A. Y. (9 de marzo de 2015). Palabras del Ministro de Justicia y del Derecho de Colombia, ante la 58 Sesión de la Comisión de Estupefacientes. Viena, Austria. 
Recuperado de: https://www.minjusticia.gov.co/Portals/0/Discurso\%20Ministro\%20de\%20Justicia\%20en\%20Viena.pdf

Sabatier, P., \& Jenkins-Smith, H. (1999). The advocacy coalition framework: An assessment. In P. Sabatier (ed.). Theories of the Policy Process. Pp. 117-166. Boulder, CO: Westview Press.

Sabatier, P., \& Weible, C. (2007). The Advocacy Coalition Framework: Innovations and Clarifications. In P. Sabatier (ed.), Theories of the policy process. Pp. 189-222. Boulder: Westview Press.

Sabatier, P., Weible, C., \& Mc Queen, K. (2009). Themes and Variations: Taking Stock of the Advocacy Coalition Framework. The Policy Studies Journal. Vol 37. Issue 1. Pp. 121-14.

Santos, F. (2009, 10 de diciembre). Fragmento de entrevista realizada en la W Radio. Recuperado de: http://www.wradio.com.co/escucha/archivo_de_audio/franciscosantos-vicepresidente-de-la-republica-de-colombia/20091210/oir/922349.aspx

Santos, J. M. (2010, 24 de septiembre). Intervención ante la Asamblea General de la Organización de las Naciones Unidas, en su 65 Periodo de Sesiones Ordinarias. Recuperado de: http://wsp.presidencia.gov.co/Prensa/2010/Septiembre/Paginas/20100924_07.aspx

Santos, J. M. (2011, 2 de diciembre). Palabras del Presidente de la República de Colombia en la apertura de la III Cumbre de Jefes de Estado y de Gobierno de América Latina y el Caribe. Caracas, Venezuela. Recuperado de: http://wsp.presidencia.gov.co/ Prensa/2011/Diciembre/Paginas/20111202_16.aspx

Santos, J. M. (2012, 24 de abril). Palabras en la instalación de la VI Cumbre de las Américas. Discurso Presidencial. Recuperado de: http://wsp.presidencia.gov.co/ Prensa/2012/Abril/Paginas/20120414_09.aspx

Santos, J. M. (2012, 26 de septiembre). Palabras del Presidente de la República de Colombia ante la Asamblea General de la Organización de las Naciones Unidas en su $67^{\circ}$ Periodo de Sesiones Ordinarias. Nueva York, Estados Unidos. Recuperado de: http://wsp.presidencia.gov.co/Prensa/2012/septiembreb/Paginas/20120926_07.aspx

Santos, J. M. (2015, 2 de junio). Palabras del Presidente de la República de Colombia en la instalación de la XXXII Conferencia Internacional de Control de Drogas. Cartagena, Colombia. Recuperado de: http://wp.presidencia.gov.co/Noticias/2015/Junio/ Paginas/20150602_04-Palabras-Presidente-Juan-Manuel-Santos-instalacionXXXII-Conferencia-Internacional-Control-Drogas.aspx

Santos, J. M. (2015, 22 de septiembre). Declaración del Presidente de la República de Colombia al poner en marcha la Estrategia Integral de Sustitución de Cultivos. Bogotá D.C., Colombia. Recuperado de: http://wp.presidencia.gov.co/Noticias/2015/ Septiembre/Paginas/20150922_01-Palabras-Declaracion-Presidente-JuanManuel-Santos-poner-marcha-Estrategia-Integral-Sustitucion-Cultivos.aspx

Santos, J. M. (22 de diciembre de 2015). Palabras del Presidente de la República de Colombia en la firma del decreto sobre uso del cannabis con fines médicos y científico. Bogotá D.C., Colombia. Recuperado de: http://es.presidencia.gov.co/noticia/Presidente-dela-Republica-firmo-decreto-sobre-uso-de-cannabis-con-fines-medicos-y-cientificos 
Semana. (9 de diciembre de 2014). Procurador en contra de uso terapéutico de la marihuana. Recuperado de: http://www.semana.com/nacion/articulo/procuradorse-declaro-en-contra-de-la-marihuana-medicinal/402508-3

Toro, C. (2013). Políticas antidrogas, narcotráfico y desarollo alternativo en Colombia en un contexto global. ¿Hacia un cambio de estrategia? En A. Vargas (Ed.), Diálogos de La Habana: Miradas múltiples desde la universidad. Pp. 211-225. Bogotá: Universidad Nacional de Colombia.

Uprimny, R., Guzmán Rodríguez, D. E., y Parra Norato, J. (2013). Penas alucinantes. La desproporción de la penalización de las drogas en Colombia. Bogotá: DeJusticia.

Uprimny, R. (2013, 10 de agosto). Uruguay: la conspiración de los razonables. El Espectador. Recuperado de: http://www.elespectador.com/opinion/uruguayconspiracion-de-los-razonables-columna-439128

Uribe, N. (2009, 23 de abril). Acta No. 36. Intervención en el primer debate al Proyecto de Acto Legislativo número 285 de 2009 Cámara, en la Comisión Primera de la Cámara de Representantes. Recuperado de: http://www.mamacoca.org/docs_de_base/Consumo/Dosis_minima_de_Uribe/nicolas_uribe_rueda_dossis_minina_23abril_2009.html

Uribe, A. (2002, 7 de agosto). Discurso de posesión como Presidente de la República de Colombia. Bogotá, D.C., Colombia. Recuperado de: http://www.alvarouribevelez.com.co/es/content/retomemos-el-lazo-unificador-de-la-ley-la-autoridaddemocratica-la-libertad-y-la-justicia

Uribe, A. (2003. 9 de febrero). Alocución del Presidente de la República de Colombia. Bogotá, D.C., Colombia. Recuperado de: http://www.alvarouribevelez.com.co/ es/content/alocucion-presidencial

Uribe, A. (2004, 25 de marzo). Intervención del Presidente de la República de Colombia ante el Consejo Permanente de la OEA. Washington D.C., Estados Unidos. Recuperado de: http://www.alvarouribevelez.com.co/es/content/intervencion-ante-elconsejo-permanente-de-la-oea

Uribe, A. (2007, 23 de noviembre). Palabras del Presidente de la República de Colombia en la reunión del Parlamento Latinoamericano. Bogotá, D.C., Colombia. Recuperado de: http://www.alvarouribevelez.com.co/es/content/palabras-del-presidenteuribe-en-la-reunion-del-parlamento-latinoamericano

Uribe, A. (2009, 23 de septiembre). Intervención del Presidente de la República de Colombia en la 64a Asamblea General de la Organización de las Naciones Unidas. Nueva York, Estados Unidos. Recuperado de: http://www.alvarouribevelez.com. co/es/content/64-asamblea-general-onu

Vega, R. (2015). La dimensión internacional del conflicto social y armado en Colombia. Injerencia de los Estados Unidos, contrainsurgencia y terrorismo de estado. En Comisión Histórica del Conflicto y sus Víctimas, Contribución al entendimiento del conflicto armado en Colombia. Pp. 1-56. Colombia

Weible, C. M., y Sabatier, P. (2006). A Guide to the Advocacy Coalition Framework. Handbook of public policy analysis. Pp. $123-136$

Weible, C., Sabatier, P., Jenkins-Smith, H., Nohrstedt, D., Henry, A., \& deLeon, P. (2011). A quarter century of the advocacy coalition framework: An introduction to the special issue. Policy Studies Journal, 39, pp. 349-360. 